Journal of Agricultural Sciences
(Tarim Bilimleri Dergisi)

\title{
Effects of Sequential Hydrogen Peroxide Applications on Salt Stress Tolerance in Bread Wheat Varieties
}

\author{
Elif Saadet ARICAN ${ }^{\mathrm{B}}$, Sefer DEMIRBAS ${ }^{\mathrm{b} *}$ (D) \\ ${ }^{a}$ Department of Agricultural Biotechnology, Graduate School of Natural and Applied Sciences, Tekirdă̆ Namık Kemal University, Tekirdă̆, TURKEY \\ bepartment of Agricultural Biotechnology, Tekirdağ Namık Kemal University, Tekirdağ, TURKEY
}

\section{ARTICLE INFO}

Research Article

Corresponding Author: Sefer DEMIRBAS, E-mail: sdemirbas@nku.edu.tr

Received: 13 March 2021 / Revised: 26 October 2021/ Accepted: 29 October 2021 / Online: 15 October 2022

\section{Cite this article}

ARICAN E S, DEMIRBAS S (2022). Effects of Sequential Hydrogen Peroxide Applications on Salt Stress Tolerance in Bread Wheat Varieties. Journal of Agricultural Sciences

(Tarim Bilimleri Dergisi), 28(4):592-602. DOI: 10.15832/ankutbd.896112

\section{ABSTRACT}

Salinity is affecting plant growth and development. Low concentration of hydrogen peroxide $\left(\mathrm{H}_{2} \mathrm{O}_{2}\right)$ has shown to be effective against various stress factors. In this study, effect of different $\mathrm{H}_{2} \mathrm{O}_{2}$ priming methods on growth, physiological and biochemical parameters in three wheat varieties (NKÜ Lider, Sultan-95, and Tosunbey) under salt stress were investigated. Salt stress $(0$ and $160 \mathrm{mM} \mathrm{NaCl})$ was applied gradually to $100 \mu \mathrm{M} \mathrm{H} \mathrm{H}_{2} \mathrm{O}_{2}$ applied $\left(-\mathrm{H}_{2} \mathrm{O}_{2}\right.$ : negative control, no application; $\mathrm{H}_{2} \mathrm{O}_{2}$ : positive control, $100 \mu \mathrm{M} \mathrm{H} \mathrm{H}_{2} \mathrm{O}_{2}$ applied; $1 \mathrm{xH}_{2} \mathrm{O}_{2}: 100 \mu \mathrm{M} \mathrm{H}_{2} \mathrm{O}_{2}$ applied one year ago; $2 \mathrm{xH}_{2} \mathrm{O}_{2}: 100 \mu \mathrm{M} \mathrm{H} \mathrm{H}_{2} \mathrm{O}_{2}$ applied second time after one year) wheat seedlings. Biochemical results showed that the lowest $\mathrm{H}_{2} \mathrm{O}_{2}$ level was in

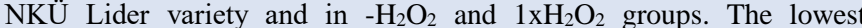
thiobarbituric acid reactive substances (TBARS) level was in Tosunbey variety and $2 \mathrm{xH}_{2} \mathrm{O}_{2}$ group. The highest superoxide dismutase (SOD) activity was in NKÜ Lider variety, all $\mathrm{H}_{2} \mathrm{O}_{2}$ pre-treatment caused an increase in SOD activity and $2 \mathrm{xH}_{2} \mathrm{O}_{2}$ pre-treatment caused the highest SOD activity. However, $\mathrm{H}_{2} \mathrm{O}_{2}$ and TBARS levels increased in all application groups except $2 \mathrm{xH}_{2} \mathrm{O}_{2}$ group, while the $\mathrm{H}_{2} \mathrm{O}_{2}$ amount increased and TBARS level decreased in $2 \mathrm{xH}_{2} \mathrm{O}_{2}$ group. $\mathrm{MnSOD}$ was not detected in any groups. CuZnSOD increased in all groups except $2 \mathrm{xH}_{2} \mathrm{O}_{2}$ groups under salt stress in Sultan-95 variety compared to FeSOD. $\mathrm{H}_{2} \mathrm{O}_{2}$ pre-treatment better tolerated salt stress, and second-applied $\mathrm{H}_{2} \mathrm{O}_{2}$ pretreatment eliminated the stress and improved plant growth. In conclusion, it was determined that $\mathrm{H}_{2} \mathrm{O}_{2}$ re-pre-treatment to wheat seeds resulted in improvement of plant growth in tolerant varieties exposed to salt stress.

Keywords: Priming, Stress biomarkers, Wheat cultivars, Superoxide dismutase activity

\section{Introduction}

Many different internal mechanisms allow plants to respond to environmental changes that have occurred during their evolutionary processes. When there is a history of exposure to many types of stress, the plant changes its response in subsequent stress conditions (Bruce et al. 2007). Stress often leads to histone or DNA modifications and changes in the expression of various susceptible genes. Some of these modifications occur in a single unstable individual. Epigenetic signs preserve in the absence of stimulants, which leads to "memorization" of stresses experienced by plants in the epigenetic environmental environment (He \& Li 2018).

Salt stress is one of the important abiotic stress factors that adversely affect plant growth and development (Ashraf 2009). The first response of the plant to salt stress is the decrease in leaf surface expansion rate and the halting of growth. The negative effects of salinity on plant growth are related to osmotic stress, food imbalance, specific ion effect and their combination (Ashraf \& Harris 2004). Increasing salinity at the soil level limits the sustainable use of the field. High salt level cause oxidative stress because of increasing reactive oxygen species (ROS) (Rashidi et al. 2021).

Plants are developing regulatory mechanisms to adapt to various environmental stresses (Saxena et al. 2016). ROS also play a holistic role as signalling molecules in the regulation of various biological processes in plants, such as growth, development, and responses to biotic and abiotic stimuli (Baxter et al. 2014). To eliminate all the negative factors that the seed encounters, accelerate germination and seedling growth and obtain high yield, various applications called priming are applied to the seeds before sowing. Priming is defined as a controlled water intake that will initiate the necessary metabolic activity for germination, but does not allow root uptake, and is defined as a physiological process in which the plant prepares to respond more quickly to abiotic stresses (Jisha et al. 2013). 
There are many used priming techniques for improving seed quality properties for example osmopriming (Farooq et al. 2017), hormopriming, hydropriming (Wani et al. 2016) and chemical priming (such as $\mathrm{H}_{2} \mathrm{O}_{2}$ ) (Savvides et al. 2016).

$\mathrm{O}_{2}-\mathrm{H}_{2} \mathrm{O}_{2}$ and $\mathrm{OH}$ excessive production of ROS causes oxidative stress in cells (Parida \& Das 2005). Numerous studies have shown that low concentrations of ROS, especially $\mathrm{H}_{2} \mathrm{O}_{2}$, are effective in priming against various abiotic stress factors (Savvides et al. 2016).

Triticum aestivum L. (wheat) is one of the most important global foods for human nutrition. Wheat, cultivation, and domestication as one of the main species closely related to the welfare of agriculture and settled societies; is one of the most grown products due to its high yield values, nutritional and processing properties. By 2050, the world population is estimated to reach nine billion, and the wheat yield of people's food needs to increase significantly (Jia et al. 2018). China is the largest wheat producer and consumer. China's annual wheat production is about 100 million tons (Shi \& Ling 2018). In Turkey, wheat production is 20.5 million tons in 2020 (Anonymous 2021).

In this study, we investigated that the effect of different $\mathrm{H}_{2} \mathrm{O}_{2}$ priming methods on root length (RL), root dry weight (RDW), shoot length (SL), shoot dry weight (SDW), relative water content (RWC), stomatal index (SIn), stomatal conductance (SC), $\mathrm{H}_{2} \mathrm{O}_{2}$ and thiobarbituric acid reactive substances (TBARS) content, SOD activity and its isoenzyme profiling in three wheat varieties (NKÜ Lider, Sultan-95, and Tosunbey) under salt stress.

\section{Material and Methods}

\subsection{Experimental material and design}

As plant material in this study were used three wheat varieties (NKÜ Lider, Sultan-95, and Tosunbey).

The study was carried out at the laboratories of Departments of Agricultural Biotechnology, Faculty of Agriculture, Tekirdağ Namik Kemal University in 2018-2019. The experiment was arranged in a randomized split-split plot design with three replications. Each group was designed to contain at least 3 pots, and a trial was established with a total of 128 pots. The varieties, $\mathrm{NaCl}$ solutions and $\mathrm{H}_{2} \mathrm{O}_{2}$ pre-treatments were allotted to main plots, subplots, and sub-subplots, respectively.

\section{2. $\mathrm{H}_{2} \mathrm{O}_{2}$ seed priming}

The seeds of each variety were soaked in the different $100 \mu \mathrm{M} \mathrm{H}_{2} \mathrm{O}_{2}$ solutions $\left(-\mathrm{H}_{2} \mathrm{O}_{2}\right.$ : negative control, no application; $\mathrm{H}_{2} \mathrm{O}_{2}$ : positive control, $100 \mu \mathrm{M} \mathrm{H}_{2} \mathrm{O}_{2}$ applied; $1 \mathrm{xH}_{2} \mathrm{O}_{2}: 100 \mu \mathrm{M} \mathrm{H}_{2} \mathrm{O}_{2}$ applied one year ago; $2 \mathrm{xH}_{2} \mathrm{O}_{2}: 100 \mu \mathrm{M} \mathrm{H}_{2} \mathrm{O}_{2}$ applied second time after one year) for $6 \mathrm{~h}$ under dark-room conditions for priming before sowing, and then the seeds were dried on filter paper at room temperature (Demirbas \& Balkan 2020).

\subsection{Plant growth condition}

After priming, the 20 seeds were sown in a pot (13 cm depth; 1.51 volume) contained perlite. The seedlings were grown in a plant growth room at $25 \pm 2 / 15 \pm 2{ }^{\circ} \mathrm{C}$ day/night with $16 \mathrm{~h}$ photoperiod, relative humidity $60 \%$ and photosynthetic flux density of approximately $250 \mu \mathrm{mol} \mathrm{m} \mathrm{m}^{-2} \mathrm{~s}^{-1}$. The salt concentrations mixed in Hoagland solution weekly gradually increased, and cultivation was carried out for 5 weeks (Hoagland \& Arnon 1950). On the 35th day, morphological, physiological, and biochemical measurements were made, and plant materials were packed for biochemical analysis and stored at $-20{ }^{\circ} \mathrm{C}$.

\subsection{Salt stress treatment and plant harvest}

Fifteen-day seedlings were watered with 0 -control and $160 \mathrm{mM} \mathrm{NaCl}$ diluted in Hoagland solutions. After salt stress application, leaves were harvested on the thirty-five-days for test and analysis.

\subsection{Plant growth parameters}

Ten randomly selected thirty-five-days-old seedlings per replicate were divided into roots and shoots. Firstly, they were measured with a ruler for root and shoot length $(\mathrm{cm})\left(\mathrm{RL}\right.$ and SL) and then, they were dried in an oven for two days at $65^{\circ} \mathrm{C}$ to determine dry weights (mg) (SDW and RDW).

\subsection{RWC test}

The fully developed leaves of the plants were taken and weighed to determine fresh weights (FW-mg). To obtain the turgid weight (TW-mg), these leaves were waited in closed petri dishes for 24 hours between distilled water and completely wet filter paper. Turgid leaves were quickly wiped with a paper towel to remove the water accumulation on them and reweighed to 
determine the TW. Then, these leaves were dried at $70{ }^{\circ} \mathrm{C}$ for 48 hours and their dry weights (DW-mg) were found. The RWC of the leaves were calculated using the following equations (Smart \& Bingham 1974):

RWC $(\%)=\frac{\text { FW-DW }}{\text { TW-DW }} \times 100$

\subsection{SIn}

The Sin level was determined from the third leaves of the wheat seedlings of 35 days. Transparent nail polish was applied to the bottom surface of the leaves cut from the plant. It was expected to dry. Later, the polish was gently peeled off the sheet and adhered to the slide and kept in room conditions until the day of measurement. Under the microscope, stoma (S) and epidermis cells $(\mathrm{E})$ in the unit area at 400x magnification were counted and the Sin value was calculated according to the formula below (Radoglou \& Jarvis 1990). Measurements were made three times from each group.

$\operatorname{SIn}(\%)=\frac{\mathrm{S}}{\mathrm{S}+\mathrm{E}} \times 100$

\subsection{SC}

The stomatal conductivity level of plants was measured from the second leaves by DECAGON brand SC-1 leaf porometer on the $35^{\text {th }}$ day of the growing period. Measurements were recorded as $\mathrm{mmol} \mathrm{m}^{-2} \mathrm{~s}^{-1}$ in triplicate from each group.

\subsection{Determination of $\mathrm{H}_{2} \mathrm{O}_{2}$ content}

$0.1 \mathrm{~g}$ leaf tissues were homogenized with $100 \mathrm{mM}$ potassium phosphate buffer ( $\mathrm{pH}$ 6.8). The homogenates were centrifuged at $14000 \mathrm{rpm}$ for $30 \mathrm{~min}$ at $4{ }^{\circ} \mathrm{C}$. After centrifugation, the supernatant reacted with peroxidase reagent. The mixture was waited at $30{ }^{\circ} \mathrm{C}$ for $10 \mathrm{~min}$, and then reaction was stopped after $1 \mathrm{~N}$ perchloric acid was added. After 10 min, supernatant was centrifuged at $14000 \mathrm{rcf}$ for $5 \mathrm{~min}$ at $4{ }^{\circ} \mathrm{C}$. The $\mathrm{H}_{2} \mathrm{O}_{2}$ content was spectrophotometrically determined at $436 \mathrm{~nm}$ according to $\mathrm{H}_{2} \mathrm{O}_{2}$ standard (Bernt \& Bergmeyer 1974).

\subsection{Determination of lipid peroxidation level}

The lipid peroxidation level of plants was assayed by determining the level of MDA. The content of TBARS was assayed by MDA (Madhava Rao \& Sresty 2000).

\subsection{Determination of total protein content and SOD activity}

The total protein content of the enzyme extract was assayed by Bradford method using BSA as a standard (Bradford 1976). The used reaction mixture for measuring SOD (EC 1.15.1.1) activity contained $33 \mu \mathrm{M}$ NBT, 10 mM L-Methionine, 0.66 mM EDTA. $\mathrm{Na}_{2}$, and $3.3 \mu \mathrm{M}$ riboflavin in $0.05 \mathrm{M} \mathrm{Na}$-phosphate buffer ( $\mathrm{pH} 7.8$ ). The test tubes containing the reaction mixture (3 $\mathrm{ml})$ and $200 \mu \mathrm{l}$ enzyme extract or distilled water were shaken and left for $10 \mathrm{~min}$ under an illumination of $300 \mu \mathrm{mol} \mathrm{m} \mathrm{s}^{-1}$ at room temperature. Maximum reduction of NBT resulted in maximum violet color in the supernatantless reaction mixture. A nonilluminated reaction mixture served as the control. The reduction of NBT was inversely proportional to the SOD activity. One unit of SOD was defined as the amount of enzyme that inhibits 50\% NBT photoreduction (Beauchamp \& Fridovich 1971; Giannipolities \& Ries 1977). A Mecasys Optizen POP UV/Vis spectrophotometer was used during all spectrophotometrically analyses.

\subsection{Identification of SOD isoenzymes}

$0.2 \mathrm{~g}$ plant leaves were homogenised with buffer solution containing $50 \mathrm{mM}$ Tris- $\mathrm{HCl} \quad(\mathrm{pH} \quad 7.8)$, $0.1 \quad \mathrm{mM}$ ethylenediaminetetraacetic acid (EDTA), $0.2 \%$ Triton $\mathrm{X}, 1 \mathrm{mM}$ phenylmethanesulfonyl fluoride (PMSF) and 2\% polyvinylpolypyrrolidone (PVPP). The homogenates were centrifuged at $14000 \mathrm{rpm}$ at $4{ }^{\circ} \mathrm{C}$ for 10 min. The supernatants were used for electrophoretic separation of SOD isoenzymes. The isoenzymes were separated by native polyacrylamide gel electrophoresis (PAGE) using 4\% stacking and 12.5\% running gels with a buffer consisting of \% 100 at $4{ }^{\circ} \mathrm{C}$ at $80 \mathrm{~mA}$ for $2 \mathrm{~h}$ with a Junyi JY-SCZ2+ mini vertical electrophoresis. The total amount of protein applied per lane was $75 \mu \mathrm{g}$. After electrophoresis, the gels were stained with riboflavin, nitroblue tetrazolium (NBT) and EDTA in Na-P buffer (pH 7.8) for 45 min in the dark. The gels were washed with $\mathrm{dIH}_{2} \mathrm{O}$ and visualized with white light (Arora \& Bhatla 2017; Beauchamp \& Fridovich 1973). Inhibitors of SOD before staining, such as $2 \mathrm{mM}$ potassium cyanide (KCN) and $3 \mathrm{mM} \mathrm{H}_{2} \mathrm{O}_{2}$, were used to detect the different types of SOD (Vitória et al. 2001). After staining, the gels were visualized under UV light using a Quantum ST5 Gel Imaging System (Vilber Lourmat). SOD isoenzymes were determined densitometric using Biocapt software.

\subsection{Statistical analysis}

This study was carried out in 3 repetitions according to the split parcels trial pattern, which was divided in random parcels. All 
physiological and biochemical data were analysed using one-way ANOVA (MSTAT) program and differences between the averages were compared with the LSD Test. Values with $\mathrm{P} \leq 0.05$ were considered statistically significant. The results are presented in the tables as mean $\pm \mathrm{SE}$.

\section{Results}

\subsection{RL and $S L$}

RLs were increased not significantly by $1.20 \%$ under salt stress as compared to untreated plants (Figure 1). RLs in the groups which were treated by $\mathrm{H}_{2} \mathrm{O}_{2}, 1 \mathrm{xH}_{2} \mathrm{O}_{2}$, and $2 \mathrm{xH}_{2} \mathrm{O}_{2}$ groups were different. RLs were decreased by $3.09 \%$ and $\% 1.58$ in $\mathrm{H}_{2} \mathrm{O}_{2}$ and $1 \mathrm{xH}_{2} \mathrm{O}_{2}$ groups, whereas they were increased by $3.56 \%$ in the $2 \mathrm{xH}_{2} \mathrm{O}_{2}$ group $(\mathrm{P}<0.01)$. We found that the Sultan-95 variety had the RL (213.74 $\mathrm{mm})$ as compared to other varieties $(\mathrm{P}>0.05)$ (Table $1 \mathrm{a})$.
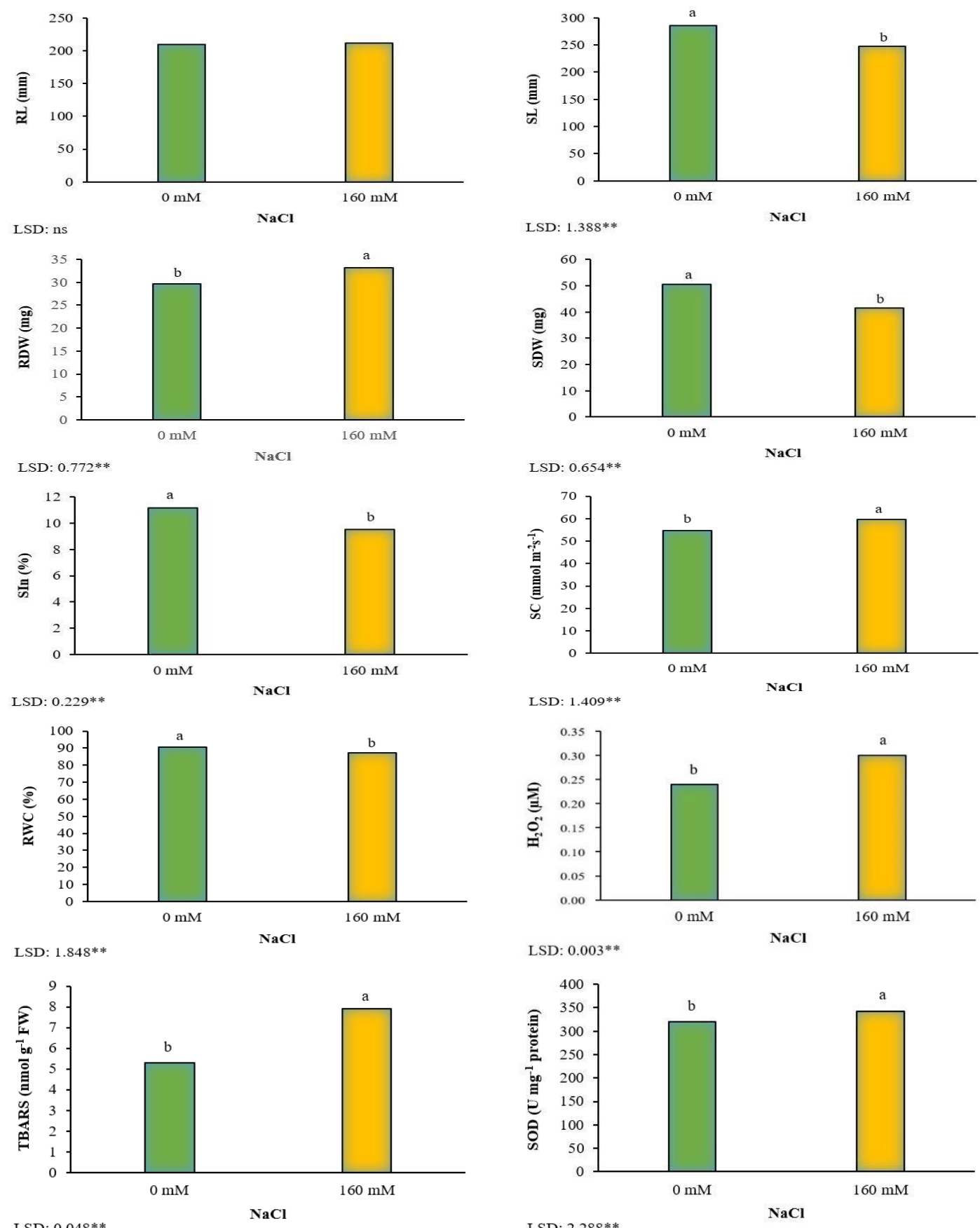

LSD: $0.048 * *$

LSD: $2.288 * *$

$\mathrm{NaCl}$

Figure 1- Effect of average $\mathrm{NaCl}$ on RL, RDW, SL, SDW, RWC, SIn, SC, $\mathrm{H}_{2} \mathrm{O}_{2}$, TBARS and SOD activity parameters in wheat seedlings. Means values followed by different letters are significantly different at $\mathrm{P}<0.05$ (* Significant correlations at $\mathrm{P}$ value $\leq 0.05$, and $* *$ at $\mathrm{P}$ value $\leq 0.01$. ns: non-significant). 
Table 1- Changes in RL (a), RDW (b), SL (c), and SDW (d) parameters of seed primed wheat seedlings with $\mathrm{H}_{2} \mathrm{O}_{2}$ under salt stress

\begin{tabular}{|c|c|c|c|c|c|c|c|}
\hline a) $R L(m m)$ & & Groups & & & & & \\
\hline Variety & $\mathrm{NaCl}(\mathrm{mM})$ & $-\mathrm{H}_{2} \mathrm{O}_{2}$ & $\mathrm{H}_{2} \mathrm{O}_{2}$ & $1 \mathrm{xH}_{2} \mathrm{O}_{2}$ & $2 \mathrm{xH}_{2} \mathrm{O}_{2}$ & Variety Average & \\
\hline & 0 & $169.56 \mathrm{j}$ & $205.67 \mathrm{f}$ & $218.33 \mathrm{~d}$ & $219.78 \mathrm{~cd}$ & NKت̈Uider & 20044 \\
\hline NKU Lider & 160 & $232.61 \mathrm{~b}$ & $196.11 \mathrm{gh} 1$ & $203.83 \mathrm{f}$ & $229.67 \mathrm{~b}$ & NKU Lider & 209.44 \\
\hline Sultan-95 & 0 & $217.00 \mathrm{~d}$ & 189.891 & $200.33 \mathrm{fgh}$ & $246.50 \mathrm{a}$ & Sultan_95 & 21374 \\
\hline & 160 & $219.89 \mathrm{~cd}$ & $226.44 b c$ & $196.17 \mathrm{gh} 1$ & $213.67 \mathrm{de}$ & Sultan-95 & 215.14 \\
\hline Tosunbey & 0 & $226.22 \mathrm{bc}$ & 194.33 h1 & $200.83 \mathrm{fgh}$ & $231.33 \mathrm{~b}$ & Tosunhey & 20992 \\
\hline I osumbey & 160 & $218.33 \mathrm{~d}$ & $199.72 \mathrm{fgh}$ & 206.83 ef & $201.78 \mathrm{fg}$ & 10sundoey & 209.92 \\
\hline $\mathrm{H}_{2} \mathrm{O}_{2}$ Average & & $213.94 \mathrm{~b}$ & $202.03 \mathrm{c}$ & $204.39 \mathrm{c}$ & $223.79 \mathrm{a}$ & & \\
\hline LSD & & $\mathrm{H}_{2} \mathrm{O}_{2}: 3.014^{*}$ & *** Varietyx & $\mathrm{NaClxH}_{2} \mathrm{O}_{2}$ & $7.382^{* *}$ & Variety: ${ }^{n s}$ & \\
\hline b) $R D W(\mathrm{mg})$ & & Groups & & & & & \\
\hline Variety & $\mathrm{NaCl}(\mathrm{mM})$ & $-\mathrm{H}_{2} \mathrm{O}_{2}$ & $\mathrm{H}_{2} \mathrm{O}_{2}$ & $1 \mathrm{xH}_{2} \mathrm{O}_{2}$ & $2 \mathrm{xH}_{2} \mathrm{O}_{2}$ & Variety Average & \\
\hline NKÜ Lider & & $17.40 \mathrm{j}$ & $34.15 \mathrm{c}-\mathrm{f}$ & $34.07 \mathrm{c}-\mathrm{f}$ & 35.52 cde & NKÜ Lider & $30.47 \mathrm{~b}$ \\
\hline & 160 & 23.631 & $29.63 \mathrm{~g}$ & $28.88 \mathrm{gh}$ & $40.50 \mathrm{a}$ & & \\
\hline Sultan-95 & 0 & $19.89 \mathrm{j}$ & $26.85 \mathrm{~h}$ & 23.351 & $38.37 \mathrm{ab}$ & Sultan-95 & $31.40 \mathrm{ab}$ \\
\hline & $\begin{array}{l}160 \\
0\end{array}$ & $\begin{array}{l}35.88 \mathrm{bc} \\
32.45 \mathrm{f}\end{array}$ & $\begin{array}{l}35.80 \mathrm{bcd} \\
28.25 \mathrm{gh}\end{array}$ & $\begin{array}{l}35.35 \text { cde } \\
3287 \text { ef }\end{array}$ & $\begin{array}{l}35.71 \mathrm{bcd} \\
3320 \mathrm{def}\end{array}$ & & \\
\hline Tosunbey & 160 & $29.77 \mathrm{~g}$ & $29.62 \mathrm{~g}$ & $36.26 \mathrm{bc}$ & $36.27 \mathrm{bc}$ & Tosunbey & $32.34 \mathrm{a}$ \\
\hline $\mathrm{H}_{2} \mathrm{O}_{2}$ Average & & $20.50 \mathrm{c}$ & $30.72 \mathrm{~b}$ & $31.80 \mathrm{~b}$ & $36.59 \mathrm{a}$ & & \\
\hline LSD & & $\mathrm{H}_{2} \mathrm{O}_{2}: 1.091$ & $1^{* *} \quad$ Variety & $\mathrm{xNaClxH}_{2} \mathrm{O}_{2}$ & $2.673^{\text {** }}$ & Variety: $1.282^{*}$ & \\
\hline c) $S L(\mathrm{~mm})$ & & Groups & & & & & \\
\hline Variety & $\mathrm{NaCl}(\mathrm{mM})$ & $-\mathrm{H}_{2} \mathrm{O}_{2}$ & $\mathrm{H}_{2} \mathrm{O}_{2}$ & $1 \mathrm{xH}_{2} \mathrm{O}_{2}$ & $2 \mathrm{xH}_{2} \mathrm{O}_{2}$ & Variety Average & \\
\hline NKÜÜLider & 0 & 340.221 & $282.89 \mathrm{f}$ & $235.28 \mathrm{j}$ & $236.28 \mathrm{ij}$ & NKÜÜLider & 252009 \\
\hline & 160 & $292.61 \mathrm{e}$ & $205.89 \mathrm{~m}$ & $183.00 \mathrm{n}$ & 240.561 & & \\
\hline Sultan-95 & 0 & $330.28 \mathrm{~b}$ & $284.56 \mathrm{f}$ & 218.001 & $248.56 \mathrm{~h}$ & Sultan-95 & $259.13 \mathrm{~b}$ \\
\hline Sultan-95 & 160 & $280.06 \mathrm{f}$ & 215.781 & $227.00 \mathrm{k}$ & $268.78 \mathrm{~g}$ & Sultan-95 & \\
\hline Tosunbey & 0 & $337.78 \mathrm{a}$ & $322.56 \mathrm{c}$ & $298.50 \mathrm{~d}$ & $289.83 \mathrm{e}$ & Tosunbey & $288.83 \mathrm{a}$ \\
\hline Tosumbey & 160 & $289.44 \mathrm{e}$ & $294.00 \mathrm{de}$ & $231.67 \mathrm{jk}$ & $246.83 \mathrm{~h}$ & Tosunbey & $200.05 \mathrm{~d}$ \\
\hline $\mathrm{H}_{2} \mathrm{O}_{2}$ Average & & $311.73 \mathrm{a}$ & $267.61 \mathrm{~b}$ & $232.24 \mathrm{~d}$ & $255.11 \mathrm{c}$ & & \\
\hline LSD & & $\mathrm{H}_{2} \mathrm{O}_{2}: 1.963$ & $3^{* *} \quad$ Variet & $\mathrm{xNaClxH}_{2} \mathrm{O}_{2}$ & $4.808^{* *}$ & Variety: $3.061^{* *}$ & \\
\hline
\end{tabular}

\begin{tabular}{llllllll}
\hline d) $\boldsymbol{S D W}(\boldsymbol{m g})$ & \multicolumn{7}{c}{ Groups } \\
\hline Variety & $\mathrm{NaCl}(\mathrm{mM})$ & $-\mathrm{H}_{2} \mathrm{O}_{2}$ & $\mathrm{H}_{2} \mathrm{O}_{2}$ & $1 \mathrm{xH}_{2} \mathrm{O}_{2}$ & $2 \mathrm{xH}_{2} \mathrm{O}_{2}$ & Variety Average & \\
NKÜ Lider & 0 & $57.24 \mathrm{~b}$ & $52.45 \mathrm{c}$ & $44.13 \mathrm{~g}$ & $46.86 \mathrm{f}$ & NKÜ Lider & $45.41 \mathrm{~b}$ \\
& 160 & $44.33 \mathrm{~g}$ & $41.83 \mathrm{~h} 1$ & $34.69 \mathrm{j}$ & $41.71 \mathrm{~h} 1$ & & \\
Sultan-95 & 0 & $46.97 \mathrm{f}$ & $49.55 \mathrm{de}$ & $34.38 \mathrm{j}$ & $49.75 \mathrm{de}$ & Sultan-95 & $42.99 \mathrm{c}$ \\
& 160 & $42.55 \mathrm{gh}$ & $41.19 \mathrm{~h} 1$ & 39.831 & $39.67 \mathrm{i}$ & & $49.94 \mathrm{a}$ \\
Tosunbey & 0 & $63.71 \mathrm{a}$ & $62.60 \mathrm{a}$ & $50.92 \mathrm{~cd}$ & $48.61 \mathrm{ef}$ & Tosunbey & \\
$\mathrm{H}_{2} \mathrm{O}_{2}$ Average & 160 & $47.71 \mathrm{ef}$ & $48.88 \mathrm{def}$ & $44.27 \mathrm{~g}$ & $32.83 \mathrm{j}$ & & \\
\hline LSD & $50.42 \mathrm{a}$ & $49.42 \mathrm{~b}$ & $41.37 \mathrm{~d}$ & $43.24 \mathrm{c}$ & & \\
\hline
\end{tabular}

*: Significant correlations at $\mathrm{P}$ value $\leq 0.05$, and **: at $\mathrm{P}$ value $\leq 0.01$. ns: non-significant

SLs were decreased by $13.11 \%(\mathrm{P}<0.01)$ under salt stress as compared to untreated plants (Figure 1). SLs were decreased by $14.15 \%, 25.50 \%$ and $\% 18.16$ in $\mathrm{H}_{2} \mathrm{O}_{2}$ and $1 \mathrm{xH}_{2} \mathrm{O}_{2}$, and $2 \mathrm{xH}_{2} \mathrm{O}_{2}$ groups $(\mathrm{P}<0.01)$. We found that the Tosunbey variety had the longest shoot $(288.83 \mathrm{~mm})(\mathrm{P}<0.01)$ as compared to other varieties (Table $1 \mathrm{c})$.

\section{2. $R D W$ and $S D W$}

RDW was increased significantly by $11.48 \%$ under salt stress as compared to untreated plants (Figure 1). RDW in the groups which were treated by $\mathrm{H}_{2} \mathrm{O}_{2}, 1 \mathrm{xH}_{2} \mathrm{O}_{2}$, and $2 \mathrm{xH}_{2} \mathrm{O}_{2}$ groups were different. RDW was increased by $49.85 \%, 55.12 \%$ and $78.49 \%$ in $\mathrm{H}_{2} \mathrm{O}_{2}, 1 \mathrm{xH}_{2} \mathrm{O}_{2}$ and $2 \mathrm{xH}_{2} \mathrm{O}_{2}$ groups $(\mathrm{P}<0.01)$. We found that the Tosunbey variety had the highest dry root weight $(32.34 \mathrm{mg})$ $(\mathrm{P}<0.01)$ as compared to other varieties (Table $1 \mathrm{~b})$.

SDW was decreased by $17.75 \%(\mathrm{P}<0.01)$ under salt stress as compared to untreated plants (Figure 1$)$. SDW was decreased by $1.98 \%, 17.95 \%$ and $14.24 \%$ in $\mathrm{H}_{2} \mathrm{O}_{2}$ and $1 \mathrm{xH}_{2} \mathrm{O}_{2}$ and $2 \mathrm{xH}_{2} \mathrm{O}_{2}$ groups $(\mathrm{P}<0.01)$. We found that the Tosunbey variety had the highest dry shoot weight $(49.94 \mathrm{mg})(\mathrm{P}<0.01)$ as compared to other varieties (Table 1d). 


\section{3. $R W C$}

RWC was decreased not significantly under salt stress as compared to untreated plants (Figure 1). RWC in the groups which were treated by $\mathrm{H}_{2} \mathrm{O}_{2}, 1 \mathrm{xH}_{2} \mathrm{O}_{2}$, and $2 \mathrm{xH}_{2} \mathrm{O}_{2}$ groups were different. RWC was increased not significantly by $2.59 \%$ and $0.80 \%$ in $\mathrm{H}_{2} \mathrm{O}_{2}$ and $2 \mathrm{xH}_{2} \mathrm{O}_{2}$ groups, whereas they were decreased by $0.20 \%$ in $1 \mathrm{xH}_{2} \mathrm{O}_{2}$ group. We found that the Sultan-95 variety had the highest RWC (90.51\%) as compared to other varieties (P>0.05) (Table 2a).

Table 2- Changes in RWC (a), SIn (b) and SC (c) parameters of seed primed wheat seedlings with $\mathrm{H}_{2} \mathrm{O}_{2}$ under salt stress

\begin{tabular}{|c|c|c|c|c|c|c|c|}
\hline \multicolumn{2}{|l|}{ a) $R W C(\%)$} & \multicolumn{6}{|l|}{ Groups } \\
\hline Variety & $\mathrm{NaCl}(\mathrm{mM})$ & $-\mathrm{H}_{2} \mathrm{O}_{2}$ & $\mathrm{H}_{2} \mathrm{O}_{2}$ & $1 \mathrm{xH}_{2} \mathrm{O}_{2}$ & $2 \mathrm{xH}_{2} \mathrm{O}_{2}$ & \multicolumn{2}{|l|}{ Variety Average } \\
\hline \multirow{2}{*}{ NKÜ Lider } & 0 & 91.32 & 94.04 & 87.72 & 90.87 & \multirow{2}{*}{ NKÜ Lider } & \multirow{2}{*}{89.13} \\
\hline & 160 & 87.55 & 89.23 & 84.08 & 88.23 & & \\
\hline \multirow{2}{*}{ Sultan-95 } & 0 & 88.11 & 91.87 & 91.97 & 92.74 & \multirow{2}{*}{ Sultan-95 } & \multirow{2}{*}{90.51} \\
\hline & 160 & 87.92 & 91.57 & 87.94 & 91.95 & & \\
\hline \multirow{2}{*}{ Tosunbey } & 0 & 89.39 & 91.48 & 88.12 & 91.07 & \multirow{3}{*}{ Tosunbey } & \multirow{3}{*}{87.46} \\
\hline & 160 & 85.70 & 85.50 & 89.06 & 79.36 & & \\
\hline \multicolumn{2}{|c|}{$\mathrm{H}_{2} \mathrm{O}_{2}$ Average } & 88.33 & 90.62 & 88.15 & 89.04 & & \\
\hline \multicolumn{2}{|c|}{ LSD } & $\mathrm{H}_{2} \mathrm{O}_{2}:^{\text {ns }}$ & \multicolumn{3}{|c|}{ Varietyx $\mathrm{NaClxH}_{2} \mathrm{O}_{2}:^{\text {:ns }}$} & \multicolumn{2}{|l|}{ Variety: ${ }^{\text {ns }}$} \\
\hline \multicolumn{2}{|l|}{ b) $\operatorname{SIn}(\%)$} & \multicolumn{4}{|l|}{ Groups } & & \\
\hline Variety & $\mathrm{NaCl}(\mathrm{mM})$ & $-\mathrm{H}_{2} \mathrm{O}_{2}$ & $\mathrm{H}_{2} \mathrm{O}_{2}$ & $1 \mathrm{xH}_{2} \mathrm{O}_{2}$ & $2 \mathrm{xH}_{2} \mathrm{O}_{2}$ & \multicolumn{2}{|l|}{ Variety Average } \\
\hline NKÜ Lider & & $\begin{array}{l}8.98 \mathrm{jk} \\
1006 \mathrm{gh}\end{array}$ & $\begin{array}{l}18.30 \mathrm{a} \\
14.15 \mathrm{c}\end{array}$ & $\begin{array}{l}12.29 \mathrm{~d} \\
10.68 \mathrm{efg}\end{array}$ & $\begin{array}{l}6.70 \mathrm{~m} \\
6.87 \mathrm{~m}\end{array}$ & NKÜ Lider & $11.01 \mathrm{a}$ \\
\hline \multirow{2}{*}{ Sultan-95 } & 0 & $9.85 \mathrm{hl}$ & 8.091 & $9.071 \mathrm{jk}$ & $17.22 \mathrm{~b}$ & \multirow{2}{*}{ Sultan-95 } & \multirow{2}{*}{$9.66 \mathrm{c}$} \\
\hline & 160 & $6.42 \mathrm{mn}$ & $9.66 \mathrm{hij}$ & $11.24 \mathrm{e}$ & 5.73 no & & \\
\hline \multirow{2}{*}{ Tosunbey } & 0 & $8.70 \mathrm{kl}$ & $10.40 \mathrm{fgh}$ & $6.09 \mathrm{mn}$ & $17.92 \mathrm{ab}$ & \multirow{3}{*}{ Tosunbey } & \multirow{3}{*}{$10.31 \mathrm{~b}$} \\
\hline & 160 & $12.39 \mathrm{~d}$ & $11.01 \mathrm{ef}$ & 10.98 ef & 4.98 o & & \\
\hline \multicolumn{2}{|c|}{$\mathrm{H}_{2} \mathrm{O}_{2}$ Average } & $9.40 \mathrm{c}$ & $11.94 \mathrm{a}$ & $10.06 \mathrm{~b}$ & $9.90 \mathrm{~b}$ & & \\
\hline LSD & & $\mathrm{H}_{2} \mathrm{O}_{2}: 0.3$ & ** $\quad$ Variet & $\mathrm{xNaClxH}_{2}$ & $: 0.793^{* *}$ & Variety: $0.321^{* *}$ & \\
\hline c) $S C$ (mmol & $\left.-{ }^{-2} S^{-1}\right)$ & Groups & & & & & \\
\hline Variety & $\mathrm{NaCl}(\mathrm{mM})$ & $-\mathrm{H}_{2} \mathrm{O}_{2}$ & $\mathrm{H}_{2} \mathrm{O}_{2}$ & $1 \mathrm{xH}_{2} \mathrm{O}_{2}$ & $2 \mathrm{xH}_{2} \mathrm{O}_{2}$ & Variety Average & \\
\hline NKÜ Lider & & $58.50 \mathrm{c}-\mathrm{h}$ & $56.37 \mathrm{f}-\mathrm{j}$ & $52.601-1$ & $57.80 \mathrm{~d}-\mathrm{h}$ & NKÜ Lider & 57.80 \\
\hline & $\begin{array}{l}160 \\
0\end{array}$ & $\begin{array}{l}54.53 \mathrm{~h}-1 \\
50.401\end{array}$ & $\begin{array}{l}59.83 \mathrm{~b}-\mathrm{f} \\
51.47 \mathrm{kl}\end{array}$ & $\begin{array}{l}62.90 \mathrm{abc} \\
56.67 \mathrm{e}-1\end{array}$ & $\begin{array}{l}59.90 \mathrm{~b}-\mathrm{f} \\
59.43 \mathrm{~b}-\mathrm{g}\end{array}$ & & \\
\hline Sultan-95 & 160 & $54.70 \mathrm{~g}-1$ & $58.03 \mathrm{c}-\mathrm{h}$ & $62.37 \mathrm{a}-\mathrm{d}$ & $51.57 \mathrm{jkl}$ & Sultan-95 & 55.58 \\
\hline Tosunhev & 0 & $55.77 \mathrm{f}-\mathrm{k}$ & $55.97 \mathrm{f}-\mathrm{k}$ & $56.07 \mathrm{f}-\mathrm{k}$ & $45.43 \mathrm{~m}$ & Tocunbey & \\
\hline 10sunbey & 160 & $62.40 \mathrm{a}-\mathrm{d}$ & $61.47 \mathrm{a}-\mathrm{e}$ & $64.80 \mathrm{a}$ & $63.77 \mathrm{ab}$ & Iosundey & 58.21 \\
\hline $\mathrm{H}_{2} \mathrm{O}_{2}$ Averag & & $56.05 \mathrm{~b}$ & $57.18 \mathrm{~b}$ & $59.23 \mathrm{a}$ & $56.32 \mathrm{~b}$ & & \\
\hline LSD & & $\mathrm{H}_{2} \mathrm{O}_{2}: 1.9$ & ** $\quad$ Variet & $\mathrm{xNaClxH}_{2}$ & $: 4.880^{* *}$ & Variety: ${ }^{n s}$ & \\
\hline
\end{tabular}

*: Significant correlations at $\mathrm{P}$ value $\leq 0.05$, and $* *$ : at $\mathrm{P}$ value $\leq 0.01$. ns: non-significant

\section{4. $\operatorname{SIn}$}

Stomal index was decreased significantly by $14.63 \%$ under salt stress as compared to untreated plants (Figure 1). Stomal index was increased by $\mathrm{H}_{2} \mathrm{O}_{2}$ applications. Stomal index was increased by $27.02 \%, 7.02 \%$ and $5.32 \%$ in $\mathrm{H}_{2} \mathrm{O}_{2}, 1 \mathrm{xH}_{2} \mathrm{O}_{2}$ and $2 \mathrm{xH}_{2} \mathrm{O}_{2}$ groups $(\mathrm{P}<0.01)$. We found that the NKÜ Lider variety had the highest stomal index $(11.01 \%)(\mathrm{P}<0.01)$ as compared to other varieties (Table $2 b$ ).

\subsection{SC}

SC was increased significantly by $9.10 \%$ under salt stress as compared to untreated plants (Figure 1). SC in the groups which were treated by $\mathrm{H}_{2} \mathrm{O}_{2}, 1 \mathrm{xH}_{2} \mathrm{O}_{2}$, and $2 \mathrm{xH}_{2} \mathrm{O}_{2}$ groups were different. $\mathrm{SC}$ was increased by $2.02 \%, 5.67 \%$ and $0.48 \%$ in $\mathrm{H}_{2} \mathrm{O}_{2}$, $1 \mathrm{xH}_{2} \mathrm{O}_{2}$ and $2 \mathrm{xH}_{2} \mathrm{O}_{2}$ groups $(\mathrm{P}<0.01)$. We found that the Tosunbey variety had the highest SC $\left(58.21 \mathrm{mmol} \mathrm{m}^{-2} \mathrm{~s}^{-1}\right)$ as compared to other varieties $(\mathrm{P}>0.05)$ (Table $2 \mathrm{c})$.

\section{6. $\mathrm{H}_{2} \mathrm{O}_{2}$}

$\mathrm{H}_{2} \mathrm{O}_{2}$ content was increased significantly by $25.00 \%$ under salt stress as compared to untreated plants $($ Figure 1$) . \mathrm{H}_{2} \mathrm{O}_{2}$ contents were increased by $11.54 \%$ and $3.85 \%$ in $\mathrm{H}_{2} \mathrm{O}_{2}$ and $2 \mathrm{xH}_{2} \mathrm{O}_{2}$ groups $(\mathrm{P}<0.01)$. We found that the NKÜ Lider variety had the lowest $\mathrm{H}_{2} \mathrm{O}_{2}$ content $(0.26 \mu \mathrm{M})(\mathrm{P}<0.01)$ as compared to other varieties (Table $\left.3 \mathrm{a}\right)$. 
Table 3- Changes in $\mathrm{H}_{2} \mathrm{O}_{2}$ (a), TBARS (b) and SOD (c) parameters of seed primed wheat seedlings with $\mathrm{H}_{2} \mathrm{O}_{2}$ under salt stress

\begin{tabular}{|c|c|c|c|c|c|c|c|}
\hline \multicolumn{2}{|l|}{ a) $\mathrm{H}_{2} \mathrm{O}_{2}(\mu M)$} & \multicolumn{6}{|l|}{ Groups } \\
\hline Variety & $\mathrm{NaCl}(\mathrm{mM})$ & $-\mathrm{H}_{2} \mathrm{O}_{2}$ & $\mathrm{H}_{2} \mathrm{O}_{2}$ & $1 \mathrm{xH}_{2} \mathrm{O}_{2}$ & $2 \mathrm{xH}_{2} \mathrm{O}_{2}$ & Variety Ave & \multirow[b]{3}{*}{$0.26 \mathrm{c}$} \\
\hline \multirow{2}{*}{ NKÜ Lider } & 0 & $0.21 \mathrm{~lm}$ & $0.21 \mathrm{~lm}$ & $0.20 \mathrm{~m}$ & $0.27 \mathrm{fg}$ & \multirow{2}{*}{ NKÜ Lider } & \\
\hline & 160 & $0.26 \mathrm{gh}$ & $0.25 \mathrm{~h}_{1}$ & $0.35 \mathrm{~b}$ & $0.33 \mathrm{c}$ & & \\
\hline \multirow{2}{*}{ Sultan-95 } & 0 & $0.24 \mathrm{ij}$ & $0.29 \mathrm{de}$ & $0.22 \mathrm{kl}$ & $0.23 \mathrm{jk}$ & \multirow{2}{*}{ Sultan-95 } & \multirow{2}{*}{$0.28 \mathrm{a}$} \\
\hline & 160 & $0.27 \mathrm{fg}$ & $0.44 \mathrm{a}$ & $0.26 \mathrm{gh}$ & $0.25 h_{1}$ & & \\
\hline \multirow{2}{*}{ Tosunbey } & 0 & $0.30 \mathrm{~d}$ & $0.28 \mathrm{ef}$ & $0.23 \mathrm{jk}$ & $0.20 \mathrm{~m}$ & \multirow{3}{*}{ Tosunbey } & \multirow{3}{*}{$0.27 \mathrm{~b}$} \\
\hline & 160 & $0.27 \mathrm{fg}$ & $0.27 \mathrm{fg}$ & 0.28 ef & $0.33 \mathrm{c}$ & & \\
\hline \multicolumn{2}{|c|}{$\mathrm{H}_{2} \mathrm{O}_{2}$ Average } & $0.26 \mathrm{c}$ & $0.29 \mathrm{a}$ & $0.26 \mathrm{c}$ & $0.27 \mathrm{~b}$ & & \\
\hline \multicolumn{2}{|c|}{ LSD } & \multicolumn{4}{|c|}{$\mathrm{H}_{2} \mathrm{O}_{2}: 0.005^{* *} \quad$ Varie } & \multicolumn{2}{|c|}{ Variety: $0.005^{* *}$} \\
\hline \multicolumn{2}{|c|}{ b) TBARS (nmol/g FW) } & \multicolumn{4}{|l|}{ Groups } & & \\
\hline Variety & $\mathrm{NaCl}(\mathrm{mM})$ & $-\mathrm{H}_{2} \mathrm{O}_{2}$ & $\mathrm{H}_{2} \mathrm{O}_{2}$ & $1 \mathrm{xH}_{2} \mathrm{O}_{2}$ & $2 \mathrm{xH}_{2} \mathrm{O}_{2}$ & \multicolumn{2}{|c|}{ Variety Average } \\
\hline \multirow{2}{*}{ NKÜ Lider } & 0 & $6.18 \mathrm{j}$ & 6.421 & $5.11 \mathrm{o}$ & 5.801 & \multirow{2}{*}{ NKÜ Lider } & \multirow{2}{*}{$7.22 \mathrm{a}$} \\
\hline & 160 & $8.60 \mathrm{~d}$ & $10.75 \mathrm{a}$ & $7.73 \mathrm{f}$ & $7.15 \mathrm{~h}$ & & \\
\hline \multirow{2}{*}{ Sultan-95 } & 0 & $3.91 \mathrm{~s}$ & $4.86 \mathrm{p}$ & 6.381 & $4.52 \mathrm{q}$ & \multirow{2}{*}{ Sultan-95 } & \multirow{2}{*}{$6.34 \mathrm{~b}$} \\
\hline & 160 & $7.50 \mathrm{~g}$ & $9.52 \mathrm{~b}$ & $8.39 \mathrm{e}$ & $5.60 \mathrm{~m}$ & & \\
\hline \multirow{2}{*}{ Tosunbey } & 0 & $6.14 \mathrm{jk}$ & $4.90 \mathrm{p}$ & $4.13 \mathrm{r}$ & $5.32 \mathrm{n}$ & \multirow{3}{*}{ Tosunbey } & \multirow{3}{*}{$6.29 \mathrm{~b}$} \\
\hline & 160 & $7.61 \mathrm{fg}$ & $6.99 \mathrm{~h}$ & $9.18 \mathrm{c}$ & $6.01 \mathrm{k}$ & & \\
\hline \multicolumn{2}{|c|}{$\mathrm{H}_{2} \mathrm{O}_{2}$ Average } & $6.66 \mathrm{c}$ & $7.24 \mathrm{a}$ & $6.82 \mathrm{~b}$ & $5.73 \mathrm{~d}$ & & \\
\hline LSD & & \multicolumn{2}{|c|}{$\mathrm{H}_{2} \mathrm{O}_{2}: 0.068^{* *} \quad \mathrm{Va}$} & $\mathrm{xNaClxH}$ & $: 0.164^{* * *}$ & \multicolumn{2}{|c|}{ Variety: $0.052^{* *}$} \\
\hline c) SOD (U m & ${ }^{-1}$ protein) & Groups & & & & & \\
\hline Variety & $\mathrm{NaCl}(\mathrm{mM})$ & $-\mathrm{H}_{2} \mathrm{O}_{2}$ & $\mathrm{H}_{2} \mathrm{O}_{2}$ & $1 \mathrm{xH}_{2} \mathrm{O}_{2}$ & $2 \mathrm{xH}_{2} \mathrm{O}_{2}$ & Variety Ave & \\
\hline NKÜ Lider & 0 & $302.85 \mathrm{k}$ & $312.07 \mathrm{j}$ & $379.23 \mathrm{f}$ & $335.53 \mathrm{~h}$ & Lider & $40033 \mathrm{a}$ \\
\hline NKU Lider & 160 & 324.511 & $315.66 \mathrm{j}$ & $467.94 \mathrm{~b}$ & $764.84 \mathrm{a}$ & NKU Lider & $400.53 \mathrm{a}$ \\
\hline Sultan-95 & 0 & $194.81 \mathrm{q}$ & $402.08 \mathrm{e}$ & $418.31 \mathrm{~d}$ & $311.76 \mathrm{j}$ & Sultan-95 & $318.35 \mathrm{~b}$ \\
\hline Sumtan-9s & 160 & $219.84 \mathrm{p}$ & $235.82 \mathrm{o}$ & 325.071 & $439.11 \mathrm{c}$ & Sultan-9s & 510.550 \\
\hline Tosunbey & 0 & $245.27 n$ & $339.29 \mathrm{~h}$ & 326.071 & $269.50 \mathrm{~m}$ & Tosunbey & $274.20 \mathrm{c}$ \\
\hline rosumoey & 160 & $199.53 \mathrm{q}$ & $180.96 \mathrm{r}$ & $354.35 \mathrm{~g}$ & 278.631 & rosumbey & \\
\hline $\mathrm{H}_{2} \mathrm{O}_{2}$ Averag & & $247.80 \mathrm{~d}$ & $297.65 \mathrm{c}$ & $378.50 \mathrm{~b}$ & $399.90 \mathrm{a}$ & & \\
\hline LSD & & $\mathrm{H}_{2} \mathrm{O}_{2}: 3.1$ & ** $\quad$ Vari & $\mathrm{xNaClxH}$ & $7.719^{* *}$ & Variety: 3.20 & \\
\hline
\end{tabular}

*: Significant correlations at $\mathrm{P}$ value $\leq 0.05$, and **: at $\mathrm{P}$ value $\leq 0.01$. ns: non-significant

\subsection{TBARS}

TBARS level was increased significantly by $49.15 \%$ under salt stress as compared to untreated plants (Figure 1). TBARS levels in the groups which were treated by $\mathrm{H}_{2} \mathrm{O}_{2}, 1 \mathrm{xH}_{2} \mathrm{O}_{2}$, and $2 \mathrm{xH}_{2} \mathrm{O}_{2}$ groups were different. TBARS level was increased by $8.71 \%$ and $2.40 \%$ in $\mathrm{H}_{2} \mathrm{O}_{2}$ and $1 \mathrm{xH}_{2} \mathrm{O}_{2}$ groups, whereas the level was decreased by $13.96 \%$ in the $2 \mathrm{xH}_{2} \mathrm{O}_{2}$ group $(\mathrm{P}<0.01)$. We found that Tosunbey variety had the lowest TBARS level $(6.29 \mathrm{nmol} / \mathrm{g} \mathrm{FW})$ as compared to other varieties $(\mathrm{P}<0.01)($ Table $3 \mathrm{~b})$.

\subsection{SOD activity and isoenzyme profiling}

SOD activity was increased significantly by $7.02 \%$ under salt stress as compared to untreated plants (Figure 1). SOD activity was increased by $\mathrm{H}_{2} \mathrm{O}_{2}$. SOD enzyme activity was increased by $20.12 \%, 52.74 \%$ and $61.38 \%$ in $\mathrm{H}_{2} \mathrm{O}_{2}, 1 \mathrm{xH}_{2} \mathrm{O}_{2}$ and $2 \mathrm{xH}_{2} \mathrm{O}_{2}$ groups $(\mathrm{P}<0.01)$. We found that NKÜ Lider variety had the highest $\mathrm{SOD}$ activity $\left(400.33 \mathrm{U} \mathrm{mg}^{-1}\right.$ protein) $(\mathrm{P}<0.01)$ as compared to other varieties (Table $3 \mathrm{c}$ ).

We found that two SOD isoenzymes showed the activity. MnSOD isoenzyme activity was not determined in all wheat varieties. CuZnSOD isoenzyme had higher activity than FeSOD isoenzyme except in $2 \mathrm{xH}_{2} \mathrm{O}_{2}$ group in Sultan-95 variety under salt stress (Figure 2-3). 


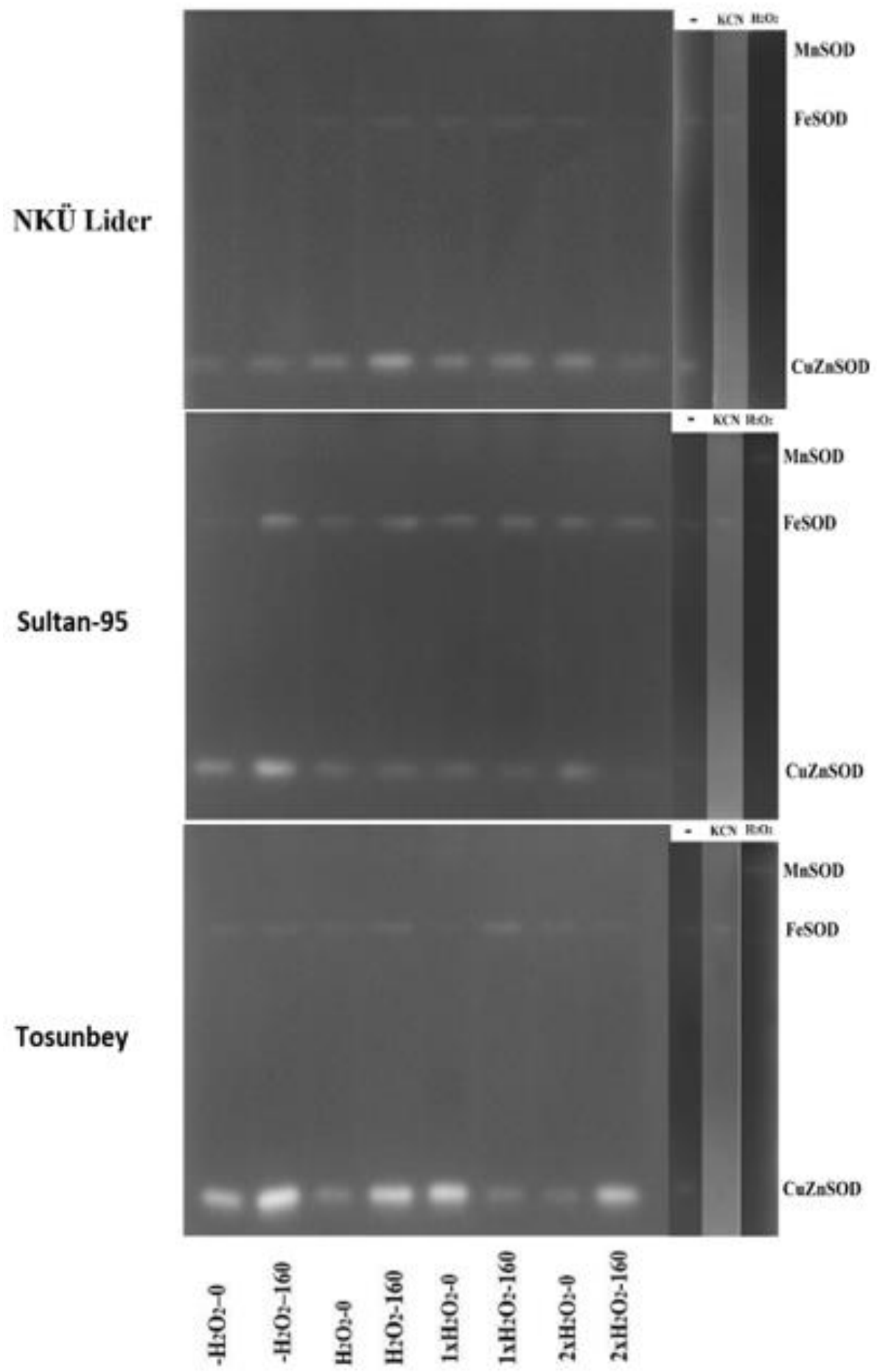

Figure 2- The effects of $\mathrm{H}_{2} \mathrm{O}_{2}$ treatments $\left(-\mathrm{H}_{2} \mathrm{O}_{2}, \mathrm{H}_{2} \mathrm{O}_{2}\right.$ and $1 \mathrm{xH}_{2} \mathrm{O}_{2}$ and $\left.2 \mathrm{xH}_{2} \mathrm{O}_{2}\right)$ on native-PAGE separation of SOD isoenzymes (MnSOD, FeSOD and CuZnSOD) in wheat varieties under salt stress (0 and $160 \mathrm{mM} \mathrm{NaCl})$

$\mathrm{CuZnSOD}$ isoenzyme activity in NKÜ Lider variety, in the $0 \mathrm{mM} \mathrm{NaCl}$ groups were found to be increased by $30.36 \%$, $18.32 \%$ and $15.84 \%$, respectively, in the $\mathrm{H}_{2} \mathrm{O}_{2}, 1 \mathrm{xH}_{2} \mathrm{O}_{2}$ and $2 \mathrm{xH}_{2} \mathrm{O}_{2}$ groups compared to the $-\mathrm{H}_{2} \mathrm{O}_{2}$ group. In Sultan-95 variety, $\mathrm{CuZnSOD}$ isoenzyme activity in the $0 \mathrm{mM} \mathrm{NaCl}$ groups increased by $9.60 \%$ and $12.42 \%$ in the $\mathrm{H}_{2} \mathrm{O}_{2}$ and $2 \mathrm{xH}_{2} \mathrm{O}_{2}$ groups, respectively, compared to the $-\mathrm{H}_{2} \mathrm{O}_{2}$ group. In Tosunbey variety, CuZnSOD isoenzyme activity in the $0 \mathrm{mM} \mathrm{NaCl}$ groups reduced by $14.44 \%$ and $23.78 \%$ in the $\mathrm{H}_{2} \mathrm{O}_{2}$ and $2 \mathrm{xH}_{2} \mathrm{O}_{2}$ groups compared to the $-\mathrm{H}_{2} \mathrm{O}_{2}$ group. It increased by $19.15 \%$ in the $1 \mathrm{xH}_{2} \mathrm{O}_{2}$ group (Figure 2-3).

$\mathrm{CuZnSOD}$ isoenzyme activity in NKÜ Lider variety under salt stress increased in all $\mathrm{H}_{2} \mathrm{O}_{2}$ groups compared to the control group. In Sultan-95 variety, only $2 \mathrm{xH}_{2} \mathrm{O}_{2}$ application decreased the activity by $74.53 \%$. In Tosunbey variety, $1 \mathrm{xH}_{2} \mathrm{O}_{2}$ application decreased the activity by $11.48 \%$ (Figure $2-3$ ). 


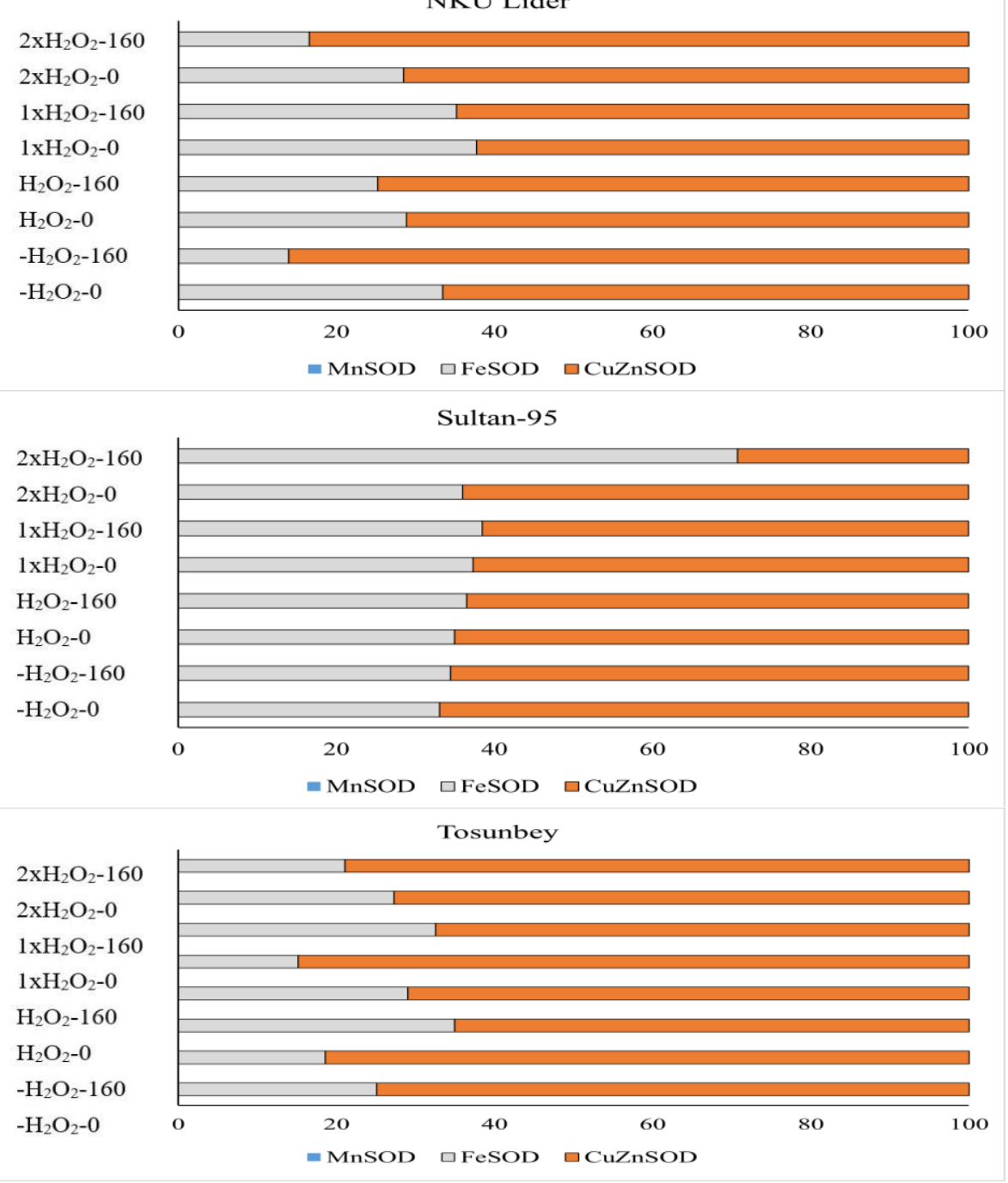

Figure 3- Effect of $\mathrm{H}_{2} \mathrm{O}_{2}$ pre-treatments $\left(-\mathrm{H}_{2} \mathrm{O}_{2}, \mathrm{H}_{2} \mathrm{O}_{2}\right.$ and $1 \mathrm{xH}_{2} \mathrm{O}_{2}$ and $\left.2 \mathrm{xH}_{2} \mathrm{O}_{2}\right)$ on percentage distribution of SOD isoenzymes under salt stress in wheat varieties (a: NKÜ Lider, b: Sultan-95, c: Tosunbey)

$1 \mathrm{xH}_{2} \mathrm{O}_{2}$ application caused an increase of $43.95 \%$ in FeSOD isoenzyme activity although $2 \mathrm{xH}_{2} \mathrm{O}_{2}$ application decreased the activity by $10.04 \%$ in NKÜ Lider variety. In Sultan-95 variety, all $\mathrm{H}_{2} \mathrm{O}_{2}$ applications caused an increase of $17 \%$ to $29 \%$ in the FeSOD isoenzyme activity. In Tosunbey variety, $1 \mathrm{xH}_{2} \mathrm{O}_{2}$ and $2 \mathrm{xH}_{2} \mathrm{O}_{2}$ applications caused decreases of $36.22 \%$ and $14.42 \%$, respectively, in the activity (Figure 2-3).

$1 \mathrm{xH}_{2} \mathrm{O}_{2}$ application caused an increase of $39.94 \%$ in the FeSOD isoenzyme activity in NKÜ Lider variety compared to the control group $\left(-\mathrm{H}_{2} \mathrm{O}_{2}-0\right)$ under salt stress. However, $-\mathrm{H}_{2} \mathrm{O}_{2}, \mathrm{H}_{2} \mathrm{O}_{2}$ and $2 \mathrm{xH}_{2} \mathrm{O}_{2}$ applications decreased the activity by $60.91 \%$, $5.55 \%$ and $56.05 \%$, respectively. In Sultan-95 variety, all $\mathrm{H}_{2} \mathrm{O}_{2}$ applications caused increases of $26 \%$ to $68 \%$. In Tosunbey variety, $\mathrm{H}_{2} \mathrm{O}_{2}$ and $1 \mathrm{xH}_{2} \mathrm{O}_{2}$ applications caused increases of $36.50 \%$ and $28.95 \%$ in the FeSOD isoenzyme activity under salt stress (Figure 2-3).

\section{Discussion}

Hydrogen peroxide causing oxidative stress in high concentrations in plants functions as a signal molecule in stimulating the plant defense system at low concentrations (Saxena et al. 2016). In previous studies, $\mathrm{H}_{2} \mathrm{O}_{2}$ has been applied by the researchers as a seed priming agent (Savvides et al. 2016) and has been reported to have a positive effect on the growth and development of wheat (Ashfaque 2014) and triticale (Demirbas \& Balkan 2020) under stress conditions. Here, we focused on how $\mathrm{H}_{2} \mathrm{O}_{2}$ affects wheat seedlings under salt stress one generation after $\mathrm{H}_{2} \mathrm{O}_{2}$ treatment. Compared to the $-\mathrm{H}_{2} \mathrm{O}_{2}$ treatment group, $\mathrm{H}_{2} \mathrm{O}_{2}$ application caused an increase in RWC, SC, SIn and RDW, while the SL, RL, and SDW decreased. $1 \mathrm{xH}_{2} \mathrm{O}_{2}$ treatment caused an increase in SC, SIn, and RDW, and a decrease in RWC, SL, RL, and SDW. While $2 \mathrm{xH}_{2} \mathrm{O}_{2}$ application caused an increase in SL and RDW, and a decrease in RWC, SC, SIn, SL, and SDW (Table 1 and 2). 
The highest RWC, RL, RDW and FeSOD isoenzyme band density was observed in Sultan-95 variety (Table 1a, b; Table 2a; Figure 2). The highest SC, SL, and SDW and the lowest TBARS level were observed in Tosunbey variety (Table 1c, 1d, 2c). The highest SIn, SOD activity and CuZnSOD isoenzyme band density and the lowest $\mathrm{H}_{2} \mathrm{O}_{2}$ level were observed in NKÜ Lider variety (Table 2b, 3c, Figure 2).

Triple interaction (Variety x $\mathrm{NaCl}_{\mathrm{X} \mathrm{H}} \mathrm{O}_{2}$ ) was statistically significant for all parameters except RWC (Table 1-3). This result indicated that there was not any effect of $\mathrm{H}_{2} \mathrm{O}_{2}$ pre-treatment on leaf water status. The correlation between the parameters showed that there was a positive relationship between RWC and SDW and SIn. This result indicated that leaf water content affected stomata density and shoot development. The positive correlation between $\mathrm{SC}$ and $\mathrm{H}_{2} \mathrm{O}_{2}$ and TBARS indicated that stomata gas exchange arranged oxidative stress in wheat seedlings. The positive correlation between RDW and $\mathrm{SOD}$ and $\mathrm{H}_{2} \mathrm{O}_{2}$ showed that increasing $\mathrm{H}_{2} \mathrm{O}_{2}$ level with SOD activity increased root growth (Table 4).

Table 4- Correlation matrix of growth, physiologic and biochemical parameters in wheat seedlings

\begin{tabular}{|c|c|c|c|c|c|c|c|c|c|c|}
\hline Variable & $R W C$ & $S C$ & $R L$ & $R D W$ & $S L$ & $S D W$ & SIn & $S O D$ & $\mathrm{H}_{2} \mathrm{O}_{2}$ & $T B A R S$ \\
\hline RWC & 1.000 & $-0.334^{* *}$ & $0.035^{\mathrm{ns}}$ & $-0.048^{n s}$ & $0.104^{\mathrm{ns}}$ & $0.287^{*}$ & $0.242^{*}$ & $0.061^{\mathrm{ns}}$ & $-0.220^{\mathrm{ns}}$ & $-0.122^{\mathrm{ns}}$ \\
\hline $\mathrm{SC}$ & & 1.000 & $0.203^{\mathrm{ns}}$ & $0.200^{\mathrm{ns}}$ & $-0.370^{* *}$ & $-0.233^{*}$ & $-0.087^{\mathrm{ns}}$ & $0.065^{\mathrm{ns}}$ & $0.349^{* *}$ & $0.457^{* *}$ \\
\hline RL & & & 1.000 & $0.455^{* *}$ & $-0.101^{\mathrm{ns}}$ & $-0.062^{\mathrm{ns}}$ & $0.221^{\mathrm{ns}}$ & $0.027^{\mathrm{ns}}$ & $0.112^{\mathrm{ns}}$ & $0.035^{\mathrm{ns}}$ \\
\hline RDW & & & & 1.000 & $-0.419^{* *}$ & $-0.219^{\mathrm{ns}}$ & $0.019^{\mathrm{ns}}$ & $0.253^{*}$ & $0.277^{*}$ & $0.121^{\mathrm{ns}}$ \\
\hline SL & & & & & 1.000 & $0.768^{* *}$ & $-0.058^{\mathrm{ns}}$ & $-0.396^{* *}$ & $-0.352^{* *}$ & $-0.512^{* *}$ \\
\hline SDW & & & & & & 1.000 & $0.213^{\mathrm{ns}}$ & $-0.283^{*}$ & $-0.259^{*}$ & $-0.372^{* *}$ \\
\hline SIn & & & & & & & 1.000 & $-0.222^{\mathrm{ns}}$ & $-0.388^{* *}$ & $0.089^{\text {ns }}$ \\
\hline SOD & & & & & & & & 1.000 & $0.152^{\mathrm{ns}}$ & $0.008^{\mathrm{ns}}$ \\
\hline $\mathrm{H}_{2} \mathrm{O}_{2}$ & & & & & & & & & 1.000 & $0.421^{* *}$ \\
\hline TBARS & & & & & & & & & & 1.000 \\
\hline
\end{tabular}

*: Significant correlations at $\mathrm{P}$ value $\leq 0.05$, and **: at $\mathrm{P}$ value $\leq 0.01$. ns: non-significant

Hydrogen peroxide $\left(\mathrm{H}_{2} \mathrm{O}_{2}\right)$, relative water content (RWC), root dry weight (RDW), root length (RL), shoot dry weight (SDW), shoot length (SL), stomatal conductance (SC), stomatal index (SIn), superoxide dismutase (SOD), thiobarbituric acid reactive substances (TBARS)

$\mathrm{H}_{2} \mathrm{O}_{2}$ level, TBARS level, SOD activity, CuZnSOD and FeSOD isoenzyme band density increased in $\mathrm{H}_{2} \mathrm{O}_{2}$ group compared to $-\mathrm{H}_{2} \mathrm{O}_{2}$ group at salt tolerance level of $\mathrm{H}_{2} \mathrm{O}_{2}$ pre-treatment. In $1 \mathrm{xH}_{2} \mathrm{O}_{2}$ group, TBARS level, SOD activity and FeSOD isoenzyme band density increased, $\mathrm{CuZnSOD}$ isoenzyme band density decreased and $\mathrm{H}_{2} \mathrm{O}_{2}$ level did not change. In the $2 \mathrm{xH}_{2} \mathrm{O}_{2}$ group, $\mathrm{H}_{2} \mathrm{O}_{2}$ level and SOD activity increased, TBARS level, CuZnSOD and FeSOD isoenzyme band density decreased (Table 3 and Figure 2). These results have shown the similarity to wheat plants' response to pre-treatment with AsA (Athar et al. 2008), K (Ahanger \& Agarwal 2017) and SNP (Ali et al. 2017) against salt stress. And salt stress in wheat plants caused an increase in SOD activity. This result is similar to studies of (He et al. 2009) and (Ashfaque 2014). MnSOD is a constitutive antioxidant enzyme in mitochondria, and it can vary between species and varieties, but in general, it is quite stable under environmental stresses (Asensio et al. 2012). In this study, MnSOD isoenzyme activity was not determined in any groups (Figure 2). This result indicated that there was not any mitochondrial response to $\mathrm{H}_{2} \mathrm{O}_{2}$ pre-treatment.

On the other hand, the increase in the amount of $\mathrm{H}_{2} \mathrm{O}_{2}$ and TBARS in the groups other than the $2 \mathrm{xH}_{2} \mathrm{O}_{2}$ application group showed a negative relationship compared to the above studies. In the $2 \mathrm{xH}_{2} \mathrm{O}_{2}$ application group, the amount of $\mathrm{H}_{2} \mathrm{O}_{2}$ increased while the amount of TBARS decreased. This result is similar to Tabassum et al. (Tabassum et al. 2017) study which they obtained with the second application of $\mathrm{CaCl}_{2}$.

\section{Conclusions}

Plant growth was improved by eliminating the pressure caused by salt stress in the development of wheat seedlings by removing the second $\mathrm{H}_{2} \mathrm{O}_{2}$ pre-application. As a result, this study demonstrated for the first time that the $\mathrm{H}_{2} \mathrm{O}_{2}$ application made before sowing in wheat contributes positively to the growth of the wheat plant by stimulating the SOD activity against salt stress. It can be said that the information obtained in this study will provide an important accumulation of knowledge for many scientific studies in which the pre-application increases the plant tolerance level, how the epigenetic mechanism is triggered, and all aspects of the antioxidant defense system will be examined more comprehensively.

\section{References}

Ahanger M A \& Agarwal R M (2017). Salinity stress induced alterations in antioxidant metabolism and nitrogen assimilation in wheat (Triticum aestivum L.) as influenced by potassium supplementation. Plant Physiology and Biochemistry 115: 449-460. https://doi.org/10.1016/j.plaphy.2017.04.017

Ali Q, Daud M K, Haider M Z, Ali S, Rizwan M, Aslam N, Noman A, Iqbal N, Shahzad F, Deeba F, Ali I \& Zhu S J (2017). Seed priming by sodium nitroprusside improves salt tolerance in wheat (Triticum aestivum L.) by enhancing physiological and biochemical parameters. Plant Physiology and Biochemistry 119: 50-58. https://doi.org/10.1016/j.plaphy.2017.08.010

Arora D \& Bhatla S C (2017). Melatonin and nitric oxide regulate sunflower seedling growth under salt stress accompanying differential expression of Cu/Zn SOD and Mn SOD. Free Radical Biology and Medicine 106: 315-328. https://doi.org/10.1016/j.freeradbiomed.2017.02.042 
Asensio A C, Gil-Monreal M, Pires L, Gogorcena Y, Aparicio-Tejo P M \& Moran J F (2012). Two Fe-superoxide dismutase families respond differently to stress and senescence in legumes. Journal of Plant Physiology 169(13): 1253-1260. https://doi.org/10.1016/j.jplph.2012.04.019.

Ashfaque $\mathrm{F}$ (2014). Exogenously applied $\mathrm{H}_{2} \mathrm{O}_{2}$ promotes proline accumulation, water relations, photosynthetic efficiency and growth of wheat (Triticum aestivum L.) under salt stress. Annual Research \& Review in Biology 4(1): 105-120 https://doi.org/10.9734/arrb/2014/5629

Ashraf M (2009). Biotechnological approach of improving plant salt tolerance using antioxidants as markers. In Biotechnology Advances 27(1): 84-93. https://doi.org/10.1016/j.biotechadv.2008.09.003

Ashraf M \& Harris P J C (2004). Potential biochemical indicators of salinity tolerance in plants. Plant Science 166(1): 3-16. https://doi.org/10.1016/j.plantsci.2003.10.024.

Athar H ur R, Khan A \& Ashraf M (2008). Exogenously applied ascorbic acid alleviates salt-induced oxidative stress in wheat. Environmental and Experimental Botany 63(1-3): 224-231 https://doi.org/10.1016/j.envexpbot.2007.10.018.

Baxter A, Mittler R \& Suzuki N (2014). ROS as key players in plant stress signalling. Journal of Experimental Botany 65(5): 1229-1240. https://doi.org/10.1093/jxb/ert375

Beauchamp C \& Fridovich I (1971). Superoxide dismutase: Improved assays and an assay applicable to acrylamide gels. Analytical Biochemistry 44(1): 276-287. https://doi.org/10.1016/0003-2697(71)90370-8

Beauchamp C O \& Fridovich I (1973). Isozymes of superoxide dismutase from wheat germ. BBA - Protein Structure 317(1): 50-64. https://doi.org/10.1016/0005-2795(73)90198-0

Bradford M M (1976). A rapid and sensitive method for the quantition of microgram quantities of protein utilizing the principle of protein-dye binding. Analytical Biochemistry 72: 248-254. https://doi.org/10.1016/0003-2697(76)90527-3

Bruce T J A, Matthes M C, Napier J A \& Pickett J A (2007). Stressful "memories" of plants: Evidence and possible mechanisms. Plant Science 173(6): 603-608. https://doi.org/10.1016/j.plantsci.2007.09.002.

Demirbas S \& Balkan A (2020). The effect of $\mathrm{H}_{2} \mathrm{O}_{2}$ pre-treatment on antioxidant enzyme activities of triticale under salt stress. JOTAF 8: 11691178. https://doi.org/10.7546/crabs.2020.08.17.

Farooq S, Hussain M, Jabran K, Hassan W, Rizwan M S \& Yasir T A (2017). Osmopriming with $\mathrm{CaCl}_{2}$ improves wheat (Triticum aestivum L.) production under water-limited environments. Environmental Science and Pollution Research 24(15): 13638-13649. https://doi.org/10.1007/s11356-017-8957-x.

Giannipolities N \& Ries S K (1977). Superoxide dismutase occurance in higher plants. Plant Physiology 59(2): 309-314. https://doi.org/10.1104/pp.59.2.309

He Y \& Li Z (2018). Epigenetic Environmental memories in plants: establishment, maintenance, and reprogramming. Trends in Genetics 34(11): 856-866. https://doi.org/10.1016/j.tig.2018.07.006

He L H, Gao Z Q \& Li R Z (2009). Pretreatment of seed with $\mathrm{H}_{2} \mathrm{O}_{2}$ enhances drought tolerance of wheat (Triticum aestivum L.) seedlings. African Journal of Biotechnology 8(22): 6151-6157. https://doi.org/10.5897/ajb09.490.

Hoagland D R \& Arnon D I (1950). The water-culture method for growing plants without soil. Circular. California Agricultural Experiment Station, 347 ( $2^{\text {nd }}$ edit $), 32$

Jia M, Guan J, Zhai Z, Geng S, Zhang X, Mao L \& Li A (2018). Wheat functional genomics in the era of next generation sequencing: An update. The Crop Journal 6(1): 7-14. https://doi.org/10.1016/j.cj.2017.09.003

Jisha K C, Vijayakumari K \& Puthur J T (2013). Seed priming for abiotic stress tolerance: an overview. Acta Physiologie Plantarum 35: 13811396. https://doi.org/10.1007/s11738-012-1186-5

Madhava Rao K V \& Sresty T V S (2000). Antioxidative parameters in the seedlings of pigeonpea (Cajanus cajan (L.) Millspaugh) in response to Zn and Ni stresses. Plant Science 157(1): 113-128. https://doi.org/10.1016/s0168-9452(00)00273-9

Parida A K \& Das A B (2005). Salt tolerance and salinity effects on plants: A review. Ecotoxicology and Environmental Safety 60(3): 324349. https://doi.org/10.1016/j.ecoenv.2004.06.010

Radoglou K M \& Jarvis P G (1990). Effects of $\mathrm{CO}_{2}$ enrichment on four poplar clones. I. growth and leaf anatomy. Annals of Botany 65(6): 617-626. https://doi.org/10.1093/oxfordjournals.aob.a087978

Rashidi V, Rahimi Darabad J, Shahbazi H, Moghaddam Vahed M \& Khalilvand E (2021). Heritability and genetic parameters of some antioxidant enzyme activities in barley (Hordeum vulgare L.) cultivars under salinity stress. Journal of Agricultural Sciences 27(2): 187194. https://doi.org/10.15832/ankutbd.597545

Savvides A, Ali S, Tester M \& Fotopoulos V (2016). Chemical priming of plants against multiple abiotic stresses: mission possible? Trends in Plant Science 21(4): 329-340. https://doi.org/10.1016/j.tplants.2015.11.003

Saxena I, Srikanth $\mathrm{S} \&$ Chen $\mathrm{Z}$ (2016). Cross talk between $\mathrm{H}_{2} \mathrm{O}_{2}$ and interacting signal molecules under plant stress response. Frontiers in Plant Science 7: 1-16. https://doi.org/10.3389/fpls.2016.00570

Shi X \& Ling H (2018). Current advances in genome sequencing of common wheat and its ancestral species. The Crop Journal 6(1): 15-21. https://doi.org/10.1016/j.cj.2017.11.001

Smart R E \& Bingham G E (1974). Rapid estimates of relative water content. Plant Physiology 53: 258-260. https://doi.org/10.1104/pp.53.2.258

Tabassum T, Farooq M, Ahmad R, Zohaib A \& Wahid A (2017). Seed priming and transgenerational drought memory improves tolerance against salt stress in bread wheat. Plant Physiology and Biochemistry 118: 362-369. https://doi.org/10.1016/j.plaphy.2017.07.007

Vitória A P, Lea P J \& Azevedo R A (2001). Antioxidant enzymes responses to cadmium in radish tissues. Phytochemistry 57(5): 701-710 .https://doi.org/10.1016/s0031-9422(01)00130-3

Wani S H, Kumar V, Shriram V \& Sah S K (2016). Phytohormones and their metabolic engineering for abiotic stress tolerance in crop plants. The Crop Journal 4(3): 162-176. https://doi.org/10.1016/j.cj.2016.01.010

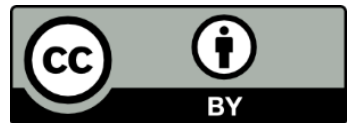

(C) 2022 by the author(s). Published by Ankara University, Faculty of Agriculture, Ankara, Turkey. This is an Open Access article distributed under the terms and conditions of the Creative Commons Attribution (CC BY) license (http://creativecommons.org/licenses/by/4.0/), which permits unrestricted use, distribution, and reproduction in any medium, provided the original work is properly cited. 